\title{
INTERPRETACIÓN CONSTITUCIONAL. ALGUNAS ALTERNATIVAS TEÓRICAS Y UNA PROPUESTA*
}

\author{
Josep Aguiló Regla \\ Universidad de Alicante
}

RESUMEN. La ponencia trata de alcanzar algunas conclusiones relativas a la interpretación constitucional a través de analizar y/o responder un conjunto de preguntas: 1. ¿Qué significa tal artículo de la constitución? 2. ¿Cómo se justifica una interpretación, una asignación de significado a un texto de la constitución? 3. ¿Cómo se hace hablar a la constitución con una sola voz? 4. ¿Cómo concebimos (o definimos) la constitución del Estado constitucional?

Palabras clave: Constitución, interpretación constitucional, Estado constitucional.

ABSTRACT. The paper tries to reach some conclusions concerning constitutional interpretation by analyzing and/or answering a set of questions: 1 . What does this article of the constitution mean? 2. How to justify an interpretation, i. e. an assignment of meaning to a text of the constitution? 3. How to make the constitution speak with one voice? 4. How to conceive -or define- the constitution of the constitutional state?

Keywords: Constitution, constitutional interpretation, constitutional State.

* Fecha de recepción: 19 de junio de 2012. Fecha de aceptación: 13 noviembre de 2012.

Este texto reproduce con pequeñas modificaciones la ponencia presentada en el «VII Encuentro de la Jurisdicción Constitucional» (en la Mesa 3 titulada «Interpretación constitucional»), con motivo de la celebración de los «20 años de la Constitución Política de Colombia de 1991» y titulado «Diálogos con el mundo». El evento tuvo lugar en Bogotá los días 10, 11 y 12 de octubre de 2011. El trabajo se ha elaborado en el marco del proyecto de investigación «Argumentación y constitucionalismo» (Ref. DER2010-21032), financiado por el Ministerio de Ciencia e Innovación español. Quiero agradecer la ayuda que, con sus comentarios y críticas, me han prestado M. AtienZA, I. Lifante, J. A. PÉREZ Lledó, A. LozAda y H. OrTiz. 


\section{INTRODUCCIÓN: ALUSIONES, ELUSIONES Y UN PLAN DE TRABAJO}

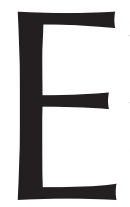

mpecemos acotando el tema de esta ponencia. Lo que aquí se va a decir queda circunscrito a la interpretación jurídica que toma como objeto de interpretación a la constitución, especialmente la parte dogmática. Quedan fuera de estudio, por tanto, los usos de la expresión «interpretación constitucional» que no entrañan eso, o que van más allá. Por ejemplo, a veces se habla de «"interpretación constitucional" de la ley» para aludir a la interpretación de la ley conforme a la constitución. Por tanto, el tema de la «interpretación constitucional», circunscrito a la interpretación jurídica de la constitución, es bastante más específico que el de la «interpretación jurídica en el Estado constitucional».

La noción de «interpretación constitucional» es compleja y problemática. Para mostrarlo tal vez sea suficiente con señalar que cada uno de los conceptos que forman la expresión, tomados por separado, «interpretación» y «constitución», resultan ya altamente controvertidos. Empecemos por «interpretación» y circunscribámoslo exclusivamente a la interpretación jurídica. La noción de «interpretación jurídica» puede problematizarse, por ejemplo, a partir de los siguientes elementos: a) Los «objetos» de la interpretación (¿qué es susceptible de ser interpretado? ¿Se interpretan textos o normas, textos o prácticas, o textos a la luz de prácticas? ¿Se interpretan acciones? ¿Y acciones institucionales?). b) Los «sujetos» de la interpretación (¿Quiénes interpretan? ¿Qué relación hay entre la interpretación de un dogmático del derecho y la de un juez? ¿Se trata de la misma operación? ¿Tiene sentido hablar de interpretación auténtica? etc.). c) La «actividad» en que consiste la interpretación (¿Qué operaciones incluye? ¿Interpretar es describir un significado o modificar un significado? ¿Tiene «naturaleza» descriptiva, adscriptiva o prescriptiva? ¿Se interpreta siempre que se aplica el derecho?). d) La «oportunidad» de la interpretación (¿Cuándo se interpreta y cuándo estamos ante un problema de interpretación? ¿Los problemas de calificación son siempre problemas de interpretación? ¿Cuál es la relación entre lagunas jurídicas e interpretación?). e) $\mathrm{El}$ «resultado» de la interpretación (¿Cuáles son sus productos? ¿Normas o enunciados interpretativos? ¿Qué relación hay entre ficciones e interpretación? $\mathrm{Y}$ formulado en términos un tanto paradójicos, ¿cuándo el resultado de una interpretación excede los límites de la interpretación?). f) La «calidad» de una interpretación (¿Cómo evaluamos una interpretación? ¿Cuándo una interpretación es correcta y/o está justificada?). Todas estas preguntas, y muchas otras que se han quedado en el tintero, ilustran bien el carácter problemático de la noción de «interpretación jurídica» ${ }^{1}$. Como es obvio, aquí no voy siquiera a intentar esbozar un principio de respuesta.

La noción de «constitución» no se queda atrás en problematicidad teórica. Para ilustrarlo basta con señalar la discusión que, en las últimas décadas, se ha generado a propósito de, por un lado, la constitucionalización de los órdenes jurídicos como cuestión de hecho ${ }^{2}$ y, por otro, el constitucionalismo como cuestión de teoría jurídi-

${ }^{1}$ Cfr. I. LIFANTE VIDAL, «Un mapa de problemas sobre la interpretación jurídica», en I. LiFANTE VIDAL (ed.), Interpretación jurídica y teoría del derecho, Palestra, 2010, 37-65.

${ }_{2}$ En mi opinión, la mejor y más clara caracterización del proceso de constitucionalización de un ordenamiento jurídico se encuentra en R. GUASTINI, Lezioni di teoria del diritto e dello Stato, Torino, Giappichelli, 2006,239 y ss. 
$\mathrm{Ca}^{3}$. Piénsese, por ejemplo, en preguntas tales como las siguientes: ¿Qué concepto de constitución asumimos cuando hablamos de interpretación constitucional? ¿Un concepto meramente formal? ¿Hay constituciones formales que no son constituciones en el sentido del Estado constitucional? ¿Cuál es la relación entre constitución y orden jurídico? ¿Hay una conexión externa (la constitución es sólo un límite al orden jurídico) o interna (el orden jurídico es un desarrollo de principios constitucionales)? ¿Qué relación hay entre el Estado de derecho (como imperio de la ley) y el Estado constitucional? ¿Implica el Estado constitucional y/o el constitucionalismo jurídico un cambio de paradigma en relación con el imperio de la ley? ¿Qué relación hay entre propiedades de las constituciones y concepciones constitucionales? Nuevamente, desarrollar todas estas preguntas - y muchas otras conectadas con ellas- desborda por completo los límites de este trabajo.

Ante tal cúmulo de preguntas ¿cómo proceder? En realidad, la alusión a tantos problemas no es más que el recurso a un tópico —el de la inabarcabilidad del territorio - con la finalidad de hacerme perdonar la elusión con que voy a proceder a continuación. En esta ponencia me propongo simplemente decir algunas cosas sobre la «interpretación constitucional», que espero que resulten significativas, aun a sabiendas de lo mucho que se dejará fuera. El plan de trabajo es el siguiente. Trataré de realizar una aproximación a «interpretación constitucional» por la vía de analizar y/o responder una «selección» de preguntas: 1. ¿Qué significa tal artículo de la constitución? 2. ¿Cómo se justifica una interpretación, una asignación de significado a un texto de la constitución? 3. ¿Cómo se hace hablar a la constitución con una sola voz? 4. ¿Cómo concebimos (o definimos) la constitución del Estado constitucional? Si todo sale según lo previsto, la respuesta a cada una de estas preguntas tiene que permitir mostrar algunas alternativas teóricas; y la sucesión de respuestas tiene que servir para perfilar, aunque sea a grandes rasgos, una propuesta a propósito de aquello que nos reúne hoy aquí: la interpretación constitucional.

\section{1. ¿QUÉ SIGNIFICA TAL ARTÍCULO DE LA CONSTITUCIÓN?}

Preguntar por el significado de un artículo de la constitución pide una respuesta que cae de lleno en la zona de claridad de la noción de «interpretación constitucional». Tiene la ventaja de que, así formulada, permite eliminar algunas complicaciones: se pregunta por el significado de un texto (el objeto de la interpretación es un texto) que se halla bien recortado (formalmente bien delimitado), un artículo. Hecha esta delimitación, puede presentarse la interpretación como una estructura que correlaciona tres enunciados diferentes: un «enunciado a interpretar», un «enunciado

3 Dos temas han acaparado la discusión en teoría del derecho en las últimas décadas. El primero de estos temas ha sido el de la vigencia y/o la superación del positivismo jurídico. Uno de los resultados producidos por esta discusión ha sido el desplazamiento de la tradicional contraposición entre iusnaturalismo y iuspositivismo por la más vigente que opone los autores (teorías) positivistas a los autores (teorías) postpositivistas. El segundo tema, no del todo independiente del anterior, ha sido el del (mal) llamado (neo-constitucionalismo o) constitucionalismo jurídico. La discusión ha versado sobre el tránsito del Estado legal de derecho al Estado constitucional de derecho; y ha girado en torno a, por un lado, cuestiones de justificación y, por otro, cuestiones metodológicas (si dicha transición implica o no un cambio de paradigma jurídico). 
interpretativo» y un «enunciado interpretado» ${ }^{4}$. La conexión entre estos tres enunciados vendrá dada por la presencia de un «problema interpretativo». Mostremos esta estructura tomando como ejemplo el art. 31.1 de la Constitución Española (en adelante $\mathrm{CE}$ ).

\begin{tabular}{|l|l|}
\hline Enunciado a interpretar & $\begin{array}{l}\text { «El hombre y la mujer tienen derecho a contraer matri- } \\
\text { monio» }\end{array}$ \\
\hline Problema interpretativo & $\begin{array}{l}\text { ¿Excluye el art. 31.1 el matrimonio entre personas del } \\
\text { mismo sexo? }\end{array}$ \\
\hline Enunciado interpretativo & $\begin{array}{l}\text { «El hombre y la mujer tienen derecho a contraer matri- } \\
\text { monio», en el art. } 31.1, \text { no significa que sólo ellos pueden } \\
\text { contraerlo entre sí». }\end{array}$ \\
\hline Enunciado interpretado & $\begin{array}{l}\text { «El hombre y la mujer tienen derecho a contraer matri- } \\
\text { monio entre sí, lo cual no excluye el matrimonio entre } \\
\text { personas del mismo sexo». }\end{array}$ \\
\hline
\end{tabular}

Esta interpretación del art. 31.1 es la que, más o menos, hizo el legislador español. La cuestión está recurrida ante el Tribunal Constitucional y, obviamente, este último tiene «poder» para hacer una interpretación alternativa. Por ejemplo, su enunciado interpretativo podría ser este: «"El hombre y la mujer tienen derecho a contraer matrimonio" significa que sólo ellos pueden contraerlo entre sí». En mi opinión, esta interpretación sería una «invención» injustificada del Tribunal, pero eso no es lo relevante ahora. Lo importante es darse cuenta de que ambos enunciados interpretativos tienen la misma estructura: usan ciertas palabras para atribuir significado a otras palabras que sólo mencionan. Esta estructura es propia de las definiciones. El término «T» significa el significado $S$, es decir: «T» significa $S$.

Siguiendo a GUASTINI y a ATIENZA puede trazarse un paralelismo entre «definir» e «interpretar» ${ }^{5}$ de forma que queden relacionados los distintos tipos de definiciones con las diferentes concepciones de la interpretación. Es decir, puede establecerse una correspondencia entre definiciones lexicográficas, estipulativas y redefiniciones, por un lado, y concepciones cognitivistas, escépticas y mixtas de la interpretación ${ }^{6}$, por otro. El siguiente cuadro muestra un resumen de dicha correspondencia.

${ }^{4}$ En el desarrollo de este epígrafe tengo muy en cuenta a M. ATIENZA, Interpretación constitucional, Bogotá, Universidad Libre de Colombia, 2010, 21-24; que, a su vez, se inspira en R. GUASTINI, Distinguendo, Torino, Giappichelli, 1996, 160 y ss.

5 Ibid.

${ }^{6}$ Escribe GUASTINI: «Se discute (desde siempre) en la doctrina cuál es el estatuto lógico de la interpretación [...] Se trata de saber si la interpretación (judicial) es un acto de conocimiento (esta es la tesis de las diversas teorías «cognoscitivistas») o por el contrario un acto de voluntad (esta es la tesis de las teorías escépticas)», en R. GUASTINI, «Teoria e ideologia dell'interpretazione costituzionales», en Lezioni di teoria del diritto e dello Stato, Torino, Giapichelli, 117. A partir de ahí, ilustra la distinción aludiendo a tres grandes teorías: a) la teoría de la interpretación de la ilustración (cognitivista); $b$ ) el neo-cognitivismo contemporáneo (mixta), y c) el escepticismo realista (escéptica). 


\begin{tabular}{|c|c|}
\hline Definición & Interpretación \\
\hline $\begin{array}{l}\text { Lexicográfica: Definir es describir el significa- } \\
\text { do con el que una comunidad lingüística usa } \\
\text { una palabra. } \\
\text { Una definición puede ser verdadera o falsa. } \\
\text { Definir es una actividad de naturaleza cog- } \\
\text { nitiva. }\end{array}$ & $\begin{array}{l}\text { Concepciones cognitivistas: Interpretar es } \\
\text { averiguar el significado de un texto. } \\
\text { Una interpretación puede ser verdadera o } \\
\text { falsa. } \\
\text { Interpretar es una actividad de naturaleza } \\
\text { cognitiva. }\end{array}$ \\
\hline $\begin{array}{l}\text { Estipulativa: Definir es crear/asignar un sig- } \\
\text { nificado a una expresión. } \\
\text { No puede ser verdadera ni falsa. } \\
\text { Es una actividad esencialmente volitiva. }\end{array}$ & $\begin{array}{l}\text { Concepciones escépticas: Interpretar es crear/ } \\
\text { decidir el significado de un texto. } \\
\text { No pueden ser verdaderas ni falsas. } \\
\text { Es una actividad volitiva. }\end{array}$ \\
\hline $\begin{array}{l}\text { Redefinición: Definir es adaptar un significa- } \\
\text { do obtenido cognitivamente para alcanzar } \\
\text { ciertos fines de claridad. } \\
\text { Está a caballo entre los otros dos tipos ante- } \\
\text { riores de definiciones. } \\
\text { Es una actividad que tiene un tramo cogniti- } \\
\text { vo y un tramo volitivo. }\end{array}$ & $\begin{array}{l}\text { Concepciones mixtas: Interpretar es elegir en- } \\
\text { tre los diferentes significados convencional- } \\
\text { mente posibles. } \\
\text { Interpretar es una actividad de naturaleza } \\
\text { mixta, tiene un tramo cognitivo y un tramo } \\
\text { volitivo. }\end{array}$ \\
\hline
\end{tabular}

No hace falta detenerse a explicar el cuadro, pues resulta - creo- suficientemente pregnante. Sí quiero, sin embargo, mostrar un límite fuerte a la comparación entre «definición»e «interpretación» tal como aquí se ha presentado. El cuadro no es del todo homogéneo porque a la izquierda lo que hay son tres conceptos diferentes de «definición»; mientras que a la derecha lo que hay son tres concepciones diferentes de la interpretación jurídica. En este sentido, los tres conceptos de definición no compiten entre sí y nadie se ve compelido a construir una concepción de las definiciones que fuerce a elegir uno de los conceptos y a descartar los otros dos. Todo el mundo maneja los tres conceptos de definición y los usa en función de los contextos, las finalidades, los tipos de discursos, etc. Por el contrario, las concepciones de la interpretación jurídica sí se presentan a sí mismas como competitivas entre sí; aceptar, por ejemplo, la concepción cognitiva de la interpretación jurídica supone rechazar las otras dos.

Sea como fuere, lo anterior nos ha permitido asentar la idea de que interpretar es asignar un significado a un texto jurídico, en nuestro caso a un artículo de la constitución. Es evidente, sin embargo, que ello no nos resuelve demasiado. Avancemos, por tanto, hacia la siguiente pregunta.

\section{2. ¿CÓMO SE JUSTIFICA UNA INTERPRETACIÓN, UNA ASIGNACIÓN DE SIGNIFICADO A UN TEXTO DE LA CONSTITUCIÓN?}

No hay gran diferencia entre hablar de criterios interpretativos y argumentos en favor de una interpretación. Los primeros ponen el acento en lo que es la guía de la 
interpretación, es decir, en la actividad de interpretar y, por tanto, parecen operar ex ante; mientras que los segundos, lo ponen en la justificación de la interpretación y, por tanto, parecen operar ex post. Por ejemplo, la «literalidad», vista como criterio interpretativo, invita a la restricción en la actividad interpretativa; pero vista como un argumento, permite justificar y/o criticar ciertas interpretaciones ya realizadas. En este sentido, puede decirse que lo que opera ex ante como un criterio interpretativo correcto, opera ex post como un argumento interpretativo válido. Y, obviamente, si las cosas son de este modo, es perfectamente posible que en determinadas circunstancias haya criterios antinómicos entre sí (que apunten a resultados incompatibles) que posteriormente operarán como razones opuestas, en favor y en contra, de una determinada interpretación. Tener esto claro es muy importante para no incurrir en los mismos errores que cometió la teoría «estándar» de la interpretación jurídica debido a sus pulsiones formalistas ${ }^{7}$.

La constitución es un texto jurídico y como tal le son aplicables «todos» los criterios y/o argumentos jurídicos que pueden utilizarse para atribuir y/o justificar significados a los textos jurídicos. Naturalmente aquí no voy a ocuparme de todos ellos ${ }^{8}$. Sí me interesa centrarme en dos rasgos que presentan los textos constitucionales, sobre todo en su parte dogmática, y que pueden justificar una cierta especificidad interpretativa de las constituciones en relación con la interpretación de las leyes. El primer rasgo es el de la rigidez de los textos constitucionales frente a la flexibilidad de los textos legales. El segundo rasgo tiene que ver con la sobreabundancia de con-

7 Como plenamente representativo de esta teoría estándar de la interpretación considérese el siguiente párrafo de LUMIA: «La interpretación jurídica consiste en el reconocimiento del significado de la norma [...]. Un primer instrumento de la interpretación está constituido, por tanto, por el instrumento literal (o textual), esto es, por el llamado "tenor" de la norma, aunque éste no siempre desemboca en resultados unívocos acerca del significado de la misma [...] Es evidente que la cuestión no podrá decidirse sin investigar el objetivo (o ratio) de la norma, es decir, el fin respecto del que la norma tiene un valor instrumental; el elemento literal ha de integrarse, pues, con el teleológico [...] el ordenamiento jurídico no resulta de una simple yuxtaposición de normas, sino que constituye un sistema en el que cada norma recibe todo su significado de su relación con las demás normas, a cuya luz, por tanto, ha de ser interpretada; al instrumento teleológico se añade, por tanto, el instrumento sistemático [...] La verdad es que el legislador cuya voluntad debe ser investigada no es sólo la del legislador originario que puso la norma, sino la del legislador actual que, aún pudiendo derogarla, la mantiene [...] de ahí por qué el intérprete no puede olvidar la dinámica del sistema, esto es, el elemento históricoevolutivo. Conviene subrayar que el elemento textual, el teleológico, el sistemático y el histórico-evolutivo no desembocan en diversos tipos de interpretación, sino que constituyen los momentos necesarios por los que debe pasar todo acto de interpretación», en G. Lumia, Principios de Teoría e ideología del derecho (trad. de A. Ruiz MigueL), Madrid, Debate, 1982, 71-72.

8 En otro lugar he escrito a propósito del método jurídico y de la interpretación: «[...] todo se ve más claro si uno se aproxima al método jurídico no como un método para hallar o descubrir soluciones, sino más bien como un método para justificar soluciones; si uno se plantea la cuestión como lo hace la teoría contemporánea de la argumentación jurídica, donde el problema no es ya el de cómo hallar la solución, sino el de cómo justificar, dar razones a favor de, la solución propuesta. Así, volviendo sobre el ejemplo de la interpretación y mirándolo desde esta perspectiva, los llamados momentos de la interpretación jurídica dejan de ser procedimientos para hallar la "interpretación correcta" para pasar a ser esquemas de argumentos susceptibles de ser utilizados a favor de la interpretación considerada correcta. En definitiva, lo que quiero resaltar es la idea de que el problema del método jurídico no es el de hallar en las normas generales las soluciones correctas a los casos particulares, sino el de justificar soluciones particulares usando normas generales. Si se miran así las cosas y se admite que, en general, puede decirse que justificar es apelar a la razón en busca de aceptación de una tesis, entonces resulta fácil entender por qué el llamado en términos teóricos "problema del método jurídico" no es otro que el de la racionalidad de las soluciones jurídicas», en J. AguiLÓ REGLA, Teoría general de las fuentes del derecho (y del orden jurídico), Barcelona, Ariel, 2000, 129. 
ceptos valorativos y de principios en los textos constitucionales. Esto último hace que, en general, la regulación constitucional sea mucho más abierta que la de las leyes. No hay que olvidar que el ideal regulativo del «imperio de la ley» implica una regulación cerrada que excluya la deliberación por parte del aplicador ${ }^{9}$. De ahora en adelante, me referiré a estos dos rasgos de las constituciones como la propiedad de la rigidez y la propiedad de la apertura regulativa, respectivamente. Quede claro, ambas propiedades son graduables y relativas. Por rigidez se entiende dificultad para el cambio del texto constitucional. Se trata de una propiedad graduable porque una constitución es más rígida cuantas más exigencias se interponen para la modificación del texto constitucional. El nivel máximo de rigidez lo representan las cláusulas pétreas o de intangibilidad y el nivel mínimo las mayorías similares a las de la legislación ordinaria ${ }^{10}$. Y es también una propiedad relativa no sólo porque cada constitución es diferente en este sentido, sino también porque la rigidez puede variar en relación con diferentes partes de una misma constitución. Por apertura regulativa se entiende el grado de deliberación «valorativa» que exige la aplicación de una norma. Se trata de una propiedad graduable, donde el nivel 0 lo representan aquellas normas cerradas cuya aplicación excluye la deliberación y el nivel máximo, aquellas otras cuya aplicación exige siempre (y en todo caso) deliberación. De la gradualidad se sigue que una norma puede ser más abierta que otra. El art. 15 de la $\mathrm{CE}^{11}$ ofrece un bonito ejemplo al respecto ya que prohíbe, en este orden, la «tortura», las «penas y tratos inhumanos y degradantes» y la «pena de muerte». El orden de más cerrada a más abierta es - parece claro- el siguiente: la prohibición de la «pena de muerte», la de la «tortura» y la de las «penas y tratos inhumanos y degradantes». Pasemos a explicar cómo estas propiedades de las constituciones, la rigidez y la apertura regulativa, pueden traducirse en peculiaridades de la interpretación constitucional respecto de la interpretación de las leyes.

9 Conforme al ideal regulativo propio del «imperio de la ley», el modelo adecuado para explicar (o dar cuenta de) la estructura de un sistema jurídico es el modelo de las reglas; entendiendo por reglas normas que correlacionan la descripción cerrada de un caso con una solución normativa. Este ideal regulativo apela a normas generales y cerradas cuya aplicación no exige (más bien excluye) cualquier forma de deliberación práctica o de valoración. Las normas abiertas, desde este ideal regulativo, son imperfecciones en la regulación cuya presencia en el sistema jurídico puede ser el resultado bien de una deficiente técnica legislativa (de un error), bien de una pura delegación de poder normativo de los órganos creadores de normas (básicamente el legislador) hacia los órganos de aplicación (los jueces y los órganos administrativos). Las normas abiertas, conforme a este modelo, al exigir deliberación por parte de los destinatarios de las mismas, suponen siempre una desviación respecto del ideal de la certeza jurídica, de la previsibilidad de las consecuencias jurídicas de las conductas.

${ }^{10}$ La rigidez efectiva de una constitución depende de una combinación de exigencias jurídico-formales y de circunstancias políticas. Entre las primeras destacan factores como los siguientes: $a$ ) el número de instituciones políticas cuyo consentimiento debe concurrir; $b$ ) el tamaño de las mayorías exigidas para la reforma, y $c$ ) la exigencia de la participación popular. Pero la rigidez efectiva depende también del contexto político, histórico, social. Como variables relevantes pueden mencionarse, por ejemplo, el sistema de partidos políticos (cuanto más disciplinados sean los partidos y más arraigada esté la cultura de coalición, tanto más fácil será reformar una constitución), el papel simbólico que desempeña la constitución en una sociedad, el papel que juegan las tradiciones políticas, etc. Sobre ello, V. FERRERES COMELLA, «Una defensa de la rigidez constitucional», en Doxa, núm. 23, 2000, 29 y ss.

${ }_{11}$ Art. 15. CE. «Todos tienen derecho a la vida y la integridad física y moral, sin que, en ningún caso, puedan ser sometidos a torturas ni a penas o tratos inhumanos o degradantes. Queda abolida la pena de muerte, salvo lo que puedan disponer las leyes penales militares para tiempos de guerra». 


\subsection{Sobre la rigidez. De las palabras de los muertos y las interpretaciones de los vivos}

Tanto la ley como la constitución son fuentes-acto, es decir, son disposiciones generales promulgadas por una autoridad ${ }^{12}$. Ahora bien, la constitución juega un papel de conservación y orientación del sistema en su conjunto que la legislación no está llamada a jugar. En este sentido, es común decir, por un lado, que hay una cierta contradicción entre la idea de constitución y la de su constante modificación ${ }^{13}$ y, por otro, que la ley es el instrumento de cambio jurídico por excelencia. Es más, si bien se considera, la oposición entre «forma constitucional» $\mathrm{y}$ «forma legal» se inventa precisamente para dotar de la mayor estabilidad posible a ciertas normas llamadas a operar como normas fundamentales dentro de un sistema jurídico-político ${ }^{14}$. En este sentido, la forma constitucional expresa tendencialmente el consenso (lo unánime, lo fundamental, lo estático, lo inmodificable); mientras que la forma legal, expresa tendencialmente el conflicto (lo mayoritario, lo fundamentado, lo dinámico, lo modificable). Conforme a esta dialéctica entre lo fundamental y lo fundamentado, la rigidez constitucional parece estar plenamente justificada frente a la flexibilidad de la legislación. Pero vista en términos diacrónicos, la rigidez constitucional nos enfrenta a un problema de racionalidad que no nos plantea la flexibilidad de la legislación. No se trata sólo de la tan discutida «objeción contramayoritaria» en términos democráticos, sino también de la cuestión de la racionalidad de una acción cuyo sentido es la mera sumisión al pasado. En efecto, la acción meramente tradicional, la acción cuyo sentido es la mera obediencia al pasado, es acción irracional ${ }^{15}$. La rigidez constitucional nos enfrenta directamente con el problema de la relación entre los muertos y los vivos; pues, el sentido del lex superior constitucional es precisamente «bloquear», «inhibir», «dificultar» (dependiendo del grado) el lex posterior legislativo en relación con ciertas materias. Por eso, la rigidez de una constitución regulativa parece enredar al constitucionalismo en una suerte de dilema. Por un lado, si una constitución es rígida, se somete a los vivos a la voluntad de los muertos. Pero, por otro lado, si una constitución no es rígida, es decir, si los derechos no están sustraídos al juego de las mayorías, entonces — suele decirse- los derechos no están garantizados, es decir, «no hay constitución». Por ello, en mi opinión, la síntesis armónica entre «los muertos» y «los vivos» desborda en gran medida la noción de sistema jurídico y sólo puede expresarse mediante nociones un tanto inestables y dialécticas

${ }_{12}$ Para una conceptualización completa de las fuentes-acto, vid. J. Aguiló Regla, Teoría general de las fuentes del derecho ( $y$ del orden jurídico), Barcelona, Ariel, 2000.

${ }^{13}$ A propósito de esto último, y teniendo en cuenta que lo que nos reúne aquí es la celebración del aniversario de la Constitución de Colombia, es oportuno decir que 30 enmiendas en 20 años tiene algo de excesivo.

${ }^{14}$ Escribe KeLSEN: «[...] Esta regla sobre la creación de las normas jurídicas esenciales del Estado, sobre la determinación de los órganos y el procedimiento de la legislación forma la Constitución en sentido propio, originario y estricto de la palabra. Es la base indispensable de las normas jurídicas que regulan la conducta recíproca de los miembros de la comunidad estatal [...] De ahí surge la idea de asegurar a la Constitución la mayor estabilidad posible, diferenciando las normas constitucionales de las normas legales y sometiendo la revisión de las primeras a un procedimiento especial, que contemple condiciones más difíciles de reunir. Aparece así la distinción entre la forma constitucional y la forma legal ordinaria». H. KELSEN, «La garantía jurisdiccional de la Constitución (La justicia constitucional)» (trad. de J. Ruiz MANERO), en H. KELSEN, Escritos sobre la democracia y el socialismo, Madrid, Debate, 1988, 114-115.

${ }^{15}$ M. Weber, Economía y sociedad, 10. ${ }^{a}$ reimpresión, México D. F., Fondo de Cultura Económica, 1993, 20. 
como la de, por ejemplo, «continuidad de una práctica constitucional» que permite, por un lado, dar cuenta del aspecto ideal del constitucionalismo y, por otro, eliminar los términos indeseables tanto de puro sometimiento al pasado como de ausencia de garantía de los derechos (de estabilización de las expectativas relativas a los derechos).

¿Cómo afecta todo ello a la interpretación de la constitución en relación con la interpretación de la ley? En mi opinión, de manera clara. Para explicarlo retomaré la vieja tensión entre autoridad y valor (o justicia) en la consideración de las normas jurídicas. Tanto la constitución como la ley son —ya lo he dicho- fuentes-acto (es decir, disposiciones, normas generales dictadas por una autoridad); sin embargo, en la interpretación de las normas constitucionales el componente autoritativo pierde mucha importancia en beneficio del componente valorativo; mientras que en la interpretación de la ley ese desplazamiento no se produce con tanta intensidad ni con tanta claridad. La interpretación de la constitución es mucho más dependiente de principios y valores que la interpretación de la ley y, en consecuencia, la interpretación literal y la intencionalista juegan mucho más papel en la interpretación de la ley que en la de la constitución. En la constitución, los muertos ponen las palabras y los vivos las interpretan a la luz de los valores que hacen que esas palabras sigan teniendo sentido para ellos; en la legislación, todos están «vivos»: tanto la autoridad que pone las palabras como aquellos que ponen los valores que las dotan de sentido ${ }^{16}$. El principio de la división de poderes no opera entre los muertos y los vivos, sino sólo entre los vivos ${ }^{17}$. Que los

16 La metáfora de los «vivos» y de los «muertos» puede resultar ambigua. Cuando se usa en términos constitucionales alude no sólo al mero paso del tiempo, pues es evidente que es perfectamente posible que una ley sea mucho más «vieja» (tenga más años) que la constitución. La diferencia es que el paso del tiempo en la ley es consentido en términos democráticos por los vivos, pues siempre tienen a su alcance la modificación de la misma. Eso es precisamente lo que trata de excluir la rigidez constitucional haciendo la modificación de la constitución altamente improbable o incluso imposible.

17 En mi opinión, el problema de la «tiranía del pasado» es irresoluble en la medida en que uno se aproxime a la constitución formal o rígida como un documento regulativo y autoritativo que trata de resolver ex ante todos los problemas jurídico-políticos que puedan plantearse. Es decir, si uno acepta el proceso constituyente como un proceso de imposición que cierra la deliberación, entonces la ilegitimidad de la forma constitucional me parece palmaria e irresoluble. Ahora bien, si uno ve el proceso constituyente como el origen de una práctica constitucional orientada por principios y valores, tal conclusión ya no es obvia. Ello es así porque la acción social orientada por principios y valores aceptados es una acción orientada hacia el futuro; y, en este sentido, la acción política de las generaciones constituidas puede ser una acción perfectamente racional; no tiene por qué ser una acción simplemente anclada en (o motivada por) la mera obediencia al pasado. Para que ello pueda ser así, las generaciones que actúan bajo una constitución tienen que ver el proceso constituyente (y en consecuencia aceptarlo) como un proceso guiado por la aceptación de ciertos principios y valores, y, así, poder entender su propia práctica constitucional como guiada también por esos mismos principios y valores. Ello, en mi opinión, es fundamental para poder afirmar — en frase que ha hecho fortuna — que «la constitución pertenece a las generaciones vivas». Esta es la razón por la que hay que insistir en la idea de que los constituyentes «reconocen» valores, no los constituyen. Lo fundamental para la estabilidad de una práctica constitucional es que las generaciones vivas se «reconozcan» en esos mismos valores aunque sin duda es posible que los «teoricen» de maneras distintas a como los hubieran teorizado los «padres fundadores». Lo que dota de continuidad a una constitución es la orientación, no precisamente todos sus contenidos concretos. En la medida en que las generaciones vivas «reconozcan» también los valores incorporados a la constitución (aunque — repito- tal vez los teoricen de maneras diferentes) la estabilidad de esa constitución está, me parece, garantizada. La clave de la continuidad constitucional está en poder interpretar la acción de los constituyentes como orientada por el reconocimiento de principios y valores y la acción de los constituidos como orientada también por el reconocimiento de esos mismos principios y valores. Cfr. J. Aguiló REGLA, Sobre la constitución del Estado constitucional, Lima-Bogotá, Palestra-Temis, 2004. 124 y ss.; y J. Aguiló RegLA, «Tener una constitución”, “darse una constitución” y “vivir en constitución”», en Isonomía. Revista de filosofía y teoría del derecho, núm. 28, 2008, 67-86. 
jueces muestren «deferencia» interpretativa al legislador tiene pleno sentido; que lo hagan con el constituyente, no ${ }^{18}$.

Esta tesis de la diferencia interpretativa entre constitución y ley a propósito de la cuestión de la rigidez no es unánimemente compartida. FERRAJOLI y DWORKIN vendrían a representar posturas incompatibles con ella aunque desde extremos opuestos. La concepción de FERRAJOLI ${ }^{19}$ podría formularse más o menos así. El derecho tiene una naturaleza autoritativa y tanto la constitución como la ley son fuentes-acto, es decir, disposiciones generales, textos normativos provenientes de una autoridad. Es más, la constitución solo tiene sentido desde el constituyente ${ }^{20}$. En la edicción de normas - sean legales o constitucionales- rige el principio voluntas, non veritas, facit legem. El modelo justificado/racional de interpretación es el vinculado al «imperio de la ley» y lo que hay que hacer es trasladarlo a la interpretación de la constitución. En la aplicación del derecho - y, por tanto también, en la interpretación — rige el principio veritas, non voluntas, facit legem. La rigidez implica ciertamente una relación sistemática de jerarquía que puede llevar a denunciar las lagunas legislativas y las antinomias que generan las leyes inconstitucionales, pero no afecta para nada a la interpretación de la constitución; es decir, a la atribución de significados a los textos constitucionales. En este sentido, la rigidez no implica peculiaridad interpretativa: no hay diferencia porque el modelo prescriptivo de interpretación para la legislación se extiende a la constitución ${ }^{21}$.

${ }^{18}$ En «Autoridades y personas», MARMOR se formulaba la siguiente pregunta: «ंes posible atribuir autoridad jurídica a una norma si su autoridad no se deriva de la autoridad de quien ha dictado esa norma?». Él básicamente respondía que no, pero en su argumentario, como buen británico, sólo tomaba como referencia al legislador (A. MARMOR, «Autoridades y personas», Doxa. Cuadernos de Filosofía del Derecho, núms. 17-18, 1995, 303). La tesis de la diferencia interpretativa aquí sostenida podría formularse de la siguiente manera: mientras que es cierto que la autoridad de una ley deriva de la autoridad del legislador, la autoridad de una constitución no deriva de la autoridad del constituyente.

${ }_{19}$ En un texto reciente, FERRAJOLI ha ofrecido un resumen, por un lado, de sus tesis sobre el constitucionalismo garantista (el constitucionalismo justificado) y, por otro, de sus diferencias con lo que él llama el «constitucionalismo principialista»: L. FERRAJOLI, «Constitucionalismo principialista y constitucionalismo garantista» (trad. de N. GuZMÁN), en Doxa. Cuadernos de Filosofía del Derecho, núm. 34, 2011, 15 y ss.

${ }^{20}$ «El decimocuarto postulado [del positivismo jurídico] excluye que puedan ser constituyentes figuras consistentes en expectativas o en no permisiones positivas o negativas. Se deducirá [...] que "constituyente" no puede ser ni un derecho, ni una obligación ni una prohibición, sólo un poder y, precisamente, aquella específica facultad que llamaremos "poder constituyente" [...] Todos los derechos en efecto, incluidos los fundamentales, consisten en expectativas [...] constituidas», en L. FerRAJOLI, Principia iuris. 1. Teoria del diritto, E. Laterza, 2007, 100-101 (la traducción es mía).

${ }^{21}$ Bien mirado, la propuesta de FERRAJOLI consiste en trasladar la noción de «estricta legalidad» del garantismo penal (cfr. L. FeRRAJOLI, Derecho y razón. Teoría del garantismo penal, Barcelona, Trotta) a la de estricta constitucionalidad en el constitucionalismo garantista. En esta asimilación entre legislación y constitución FERRAJOLI llega a escribir: «Por otro lado, debemos darnos cuenta de que la oscuridad, la vaguedad y la indeterminación del lenguaje legal, aun cuando en alguna medida ineliminables, no son simples defectos de la legislación. Son un vicio jurídico de ésta, porque violan los principios de la separación de los poderes y de la sujeción de los jueces a la ley y, por ello, comprometen el mantenimiento del edificio del estado de derecho en su totalidad. Por eso, la ciencia jurídica debería hoy retomar el programa ilustrado de G. FILANGIERI y de J. BENTHAM de una «ciencia de la legislación», integrándolo con el programa de una «ciencia de la constitución», como la llamó G. Romagnosi. Pasada la época de las primeras constituciones, que se caracterizaban inevitablemente por un lenguaje declamatorio, nada impide el desarrollo de una técnica de formulación de las normas legislativas y constitucionales — de las reglas y de los principios, como así también de sus límites y de los límites a sus límites, a su vez enunciados explícitamente- en un lenguaje lo más simple, claro y preciso posible», en L. FERRAJOLI, «Constitucionalismo principialista y constitucionalismo garantista» (trad. de N. GuZmán), en Doxa. Cuadernos de Filosofía del Derecho, núm. 34, 2011, 51-52. 
DwORKIN —o, mejor, una cierta lectura de la obra de DwORKIN porque no siempre es fácil fijar con precisión su pensamiento- se opondría también a la tesis de la diferencia, pero desde el extremo opuesto al de FeRRAJOLI. La tesis de la diferencia sostenía que en la interpretación de las normas constitucionales el componente autoritativo perdía importancia mientras que en la interpretación de la ley eso no ocurría con tanta intensidad ni con tanta claridad. Para DwORKIN la interpretación, toda la interpretación, es dependiente de valores. Más o menos su concepción podría formularse así: El derecho es una práctica interpretativa dependiente de valores; es decir, el derecho (todo él) se compone de un conjunto de reglas y de unos valores que estas reglas pretenden desarrollar. La autoridad juega un cierto papel — común en la constitución y en la legislación - en la identificación del objeto de la interpretación; es decir, en la determinación de los materiales jurídicos sobre los que versa la interpretación, en la llamada fase pre-interpretativa. Pero en las fases interpretativa y postinterpretativa se trata, respectivamente, de dotar de sentido valorativo a las reglas identificadas y de seleccionar la teoría que mejor integre los valores reconocidos ${ }^{22}$.

\subsection{Sobre la apertura regulativa. ¿Imprecisión y pluralismo?}

La propiedad de la apertura regulativa nos remite a dos cuestiones relativamente (sólo relativamente) diferentes entre sí. La primera es la de la dialéctica principiosreglas en la interpretación de los textos jurídicos; la segunda es la de la «semántica» de los conceptos «valorativos» (conceptos moral y políticamente muy «cargados»). Aquí no voy a entrar en la cuestión de los principios y las reglas; y no lo voy a hacer básicamente por dos razones. Una es que el tema de los principios y las reglas ha sido ampliamente discutido en las últimas décadas y es sobradamente conocido. Su abordaje aquí ocuparía demasiado espacio y rendiría poco. La otra razón para esta exclusión es que, bien mirado, el tema de los principios y las reglas es en parte redundante con lo dicho a propósito de la propiedad de la rigidez; pues la tesis de la diferencia interpretativa entre constitución y ley allí sostenida es fácilmente traducible en términos de principios y reglas: los enunciados constitucionales muestran una tendencia a ser interpretados como principios que no muestran los enunciados legales. Centrémonos, pues, en la otra cuestión, en la de los conceptos valorativos.

Con mucha frecuencia se oye decir que una constitución regulativa que sea democrática tiene que ser «abierta» para permitir que el sistema jurídico-político pueda reflejar las alternativas políticas y valorativas que operan a su amparo, es decir, el pluralismo. Esta forma de hablar sugiere dos ideas que no es que sean estrictamente falsas,

22 R. Dworkin, Law's Empire, Cambridge, Harvard University Press, 1986, 65 y ss. Por otro lado, es de sobra conocida la actitud de DWORKIN hacia la democracia mayoritaria como autoridad. En este sentido escribe: «La concepción constitucional de la democracia, en breve, adopta la siguiente actitud hacia el gobierno mayoritario. Democracia significa gobierno sometido a condiciones — podríamos llamarlas condiciones "democráticas" - de igual estatus para todos los ciudadanos. Cuando las instituciones mayoritarias proveen y respetan las condiciones democráticas, entonces el veredicto de estas instituciones debería ser aceptado por todos por aquella razón. Pero cuando no lo hacen, o cuando sus provisiones o respeto son insuficientes, no puede haber objeción, en nombre de la democracia, a que otros procedimientos los protejan y respeten mejor» (la trad. es mía), en R. Dworkin, Freedom's Law. The moral Reading of the American Constitution, OxfordNew York, Oxford University Press, 1996, 17. 
pero interpretadas a la ligera pueden producir una gran distorsión. La primera es que hay algo bueno en el pluralismo valorativo entendido como un hecho. Esta idea, muy arraigada en visiones simplistas de la democracia, no es más que un puro prejuicio. Tiene mucho más valor el consenso en torno a la abolición de la pena de muerte que la existencia de una división valorativa entre abolicionistas e instauracionistas. Por tanto, una cosa es gestionar correctamente el pluralismo valorativo que de hecho existe en una sociedad y otra muy distinta es otorgarle valor directamente. El valor tanto del consenso como del disenso fácticos depende del valor de la sustancia objeto de consenso y de disenso. La segunda idea equivocada consiste en considerar que «constitución abierta» es sinónimo de «constitución imprecisa» ${ }^{23}$. La apertura regulativa tiene que ver con el uso de conceptos valorativos en los textos constitucionales; y estos conceptos no pueden analizarse solo con las categorías propias de los conceptos meramente clasificatorios. Hacerlo constituye, en mi opinión, un error. La apertura regulativa puede ser perfectamente una virtud de un texto constitucional, la «mera» imprecisión no lo es nunca.

Para explicarlo tomemos de nuevo el ejemplo del art. 15 de la CE. La primera prohibición (la de la pena de muerte) es obviamente cerrada, es decir, su aplicación excluye cualquier forma de deliberación práctica; y la excluye porque, por un lado, «pena de muerte» no es un concepto valorativo (su uso no presupone el «abolicionismo» ni el «instauracionismo») y, además, es un concepto bien preciso en términos clasificatorios. Si bien se considera, en torno al concepto «pena de muerte» no funcionan de manera relevante la distinción caso regulado/caso no regulado (porque no hay imprecisión clasificatoria) ni la distinción caso fácil/caso difícil (porque no se trata de un concepto valorativo). No ocurre lo mismo con «tortura» ni con «tratos inhumanos y degradantes». Se trata, sin duda, de conceptos valorativos: no puede haber «torturas» buenas ni «tratos inhumanos y degradantes» correctos. En torno a estos conceptos tiene pleno sentido la distinción caso fácil/caso difícil. Es cierto que «tortura» es un concepto más denso que «trato inhumano y degradante» y, en consecuencia, su prohibición es mucho menos abierta; pero, en mi opinión, ni uno ni otro concepto son reducibles a su componente factual. Centrémonos en la prohibición de los tratos inhumanos y degradantes. Para determinar que Muamar el Gadafi sufrió, en el momento de su detención, un «trato inhumano y degradante» no hace falta deliberar nada: se trata de un caso fácil de aplicación de la prohibición. Ahora bien, determinar si algunos protocolos policiales de detención de sospechosos o acusados suponen un «trato inhumano y degradante» puede conllevar tener que desarrollar una intensa deliberación práctica y valorativa; en estos casos, aplicar la prohibición puede ser lo más parecido a resolver un caso difícil. Es lo que muchos sostuvieron en Francia a propósito del protocolo que se siguió en la detención de Dominique Strauss-Kahn el pasado mayo en New York.

Para entender adecuadamente el papel de los conceptos valorativos en una constitución debemos retomar la noción de práctica constitucional y distinguir

${ }_{23}$ Escribe R. GUASTINI, identificando prácticamente «regulación abierta» con «ausencia de regulación»: «En definitiva, los conceptos empleados en la formulación de los principios constitucionales son, evidentemente, conceptos jurídicos altamente indeterminados — que apelan a las doctrinas morales y/o las ideologías políticas de los intérpretes-cuya interpretación es, en consecuencia, altamente discrecional» (la traducción es mía), R. GuASTinI, Nuovi Studi sull'Interpretazione, Col. Studi di Filosofia analitica del Diritto, Roma, ARACNE, 2008, 142. 
entre el momento de «darse una constitución» y el momento de «interpretar una constitución». En el momento de darse una constitución, cualquier constituyente «responsable» tiene que enfrentar dos problemas ineliminables en la medida en que la constitución sea un acuerdo sobre lo «inmodificable». El primer problema es el del consenso, es decir, tenemos dificultades para ponernos de acuerdo sobre lo correcto. El segundo problema es el del compromiso, esto es, tenemos inseguridad para comprometernos con reglas prácticamente inmodificables porque no somos capaces de establecer en abstracto y por adelantado exhaustivamente las circunstancias en las que la regla debería regir. La conciencia de estas dos dificultades permite explicar bien el papel que los llamados acuerdos incompletamente teorizados (o acuerdos superficiales) juegan en la redacción de las constituciones ${ }^{24}$. La idea de práctica constitucional presupone, pues, que si tiene sentido llegar a tales acuerdos en el momento de darse una constitución, tiene que tener sentido interpretar los conceptos valorativos que son precisamente sus productos principales ${ }^{25}$. Una vez más, la constitución rígida y abierta desborda la concepción del derecho como sistema, como conjunto ordenado de enunciados; pues la idea de «regulación abierta» se traduce en orientación valorativa y en ese tipo especial de «deberes» que llamamos «responsabilidades». Naturalmente, todo ello apunta a exigencias de tipo deliberativo-argumentativo y al desarrollo de las actitudes adecuadas para poder satisfacerlas.

Hay dos formas alternativas a la de «práctica constitucional» de abordar la cuestión del significado y la interpretación de los conceptos valorativos. La primera, que podríamos llamar convencionalista-decisionista, es especialmente adecuada para las concepciones del derecho como sistema. Estas concepciones suelen operar con la oposición caso-regulado/caso-no-regulado, en lugar de con la oposición caso-fácil/casodifícil. La diferencia entre una y otra radica en que la noción de caso-no-regulado remite a la de discrecionalidad (entendida en términos jurídicos como mera libertad dentro del perímetro normativo) mientras que la de caso difícil remite a las nociones de deliberación y responsabilidad ${ }^{26}$. Pues bien, para esta concepción convencionalista los conceptos valorativos se comportarían grosso modo como los demás conceptos. Cuando hay convención (zona de claridad y de oscuridad) su uso y aplicación no exige realizar valoraciones; cuando no hay convención (zona de penumbra), su uso y aplicación exige simplemente decisión ${ }^{27}$.

${ }^{24}$ Sobre los acuerdos incompletamente teorizados, C. R. SunSTEIN, «Constitutional Agreements Whithout Constitutional Theories», en Ratio Iuris, vol. 13, núm. 1, mayo 2000, 117-130.

${ }_{25}$ De ello me he ocupado en J. AgUILÓ REGLA, «Sobre el constitucionalismo y la resistencia constitucional», en Doxa. Cuadernos de Filosofía del Derecho, núm. 26, 2003, 289-319.

${ }_{26}$ Sobre ello, vid. los trabajos de I. LIFANTE VIDAL, «Dos conceptos de discrecionalidad jurídica», en Doxa. Cuadernos de Filosofía del Derecho, 25, 2002, 413-419, y «Poderes discrecionales», en A. GARCíA-FIGUEROA (coord.), Racionalidad y derecho, Madrid, CEC, 2006, 107-131.

27 Un trabajo que refleja perfectamente estos planteamientos es P. E. NAVARRO, «La aplicación neutral de conceptos valorativos», en Analisi e diritto, 2007, 39 y ss. P. NAVARRO, siguiendo a C. AlChOuRRÓN y E. BuLYGIN, sostiene que el uso y la aplicación de conceptos valorativos no implica realizar valoraciones, puesto que en la medida en que exista una convención pueden ser usados descriptivamente, y que, en consecuencia, cabe su aplicación neutral. Así, puede leerse: «[...] cuando un juez aplica un concepto valorativo no es necesario que use a ese predicado para imponer sus propias valoraciones en una determinada situación, sino que puede intentar determinar a qué cosas se refieren los miembros de su comunidad mediante esos conceptos» (42). 
La segunda alternativa a la de «práctica constitucional» es considerar que la mayoría de los conceptos valorativos presentes en las constituciones son, en realidad, «conceptos esencialmente controvertidos» ${ }^{28}$, es decir, conceptos cuya característica esencial es la de carecer de una zona de claridad. Sus características serían las siguientes $^{29}: 1$. Se trata de conceptos evaluativos, es decir, de conceptos que se utilizan para asignar valor a acciones y a estados de cosas. 2. Son conceptos complejos; su caracterización requiere no solo la enunciación de un conjunto de propiedades que los ponen en contacto con otros conceptos, sino que además su uso exige la formulación de teorías que definan relaciones de prioridad entre dichas propiedades. La libertad, la igualdad, la dignidad, etc., no son aplicables directamente, requieren una concepción. 3. Son conceptos que tienen un carácter argumentativo, es decir, suelen estar envueltos en una permanente controversia. Y 4. son conceptos funcionales, es decir, se trata de conceptos que son usados para canalizar las disputas acerca de las cuestiones socialmente más relevantes; operan como el punto de «encuentro» (la arena, el ring, el foro, la cancha) en el que se ventilan las disputas políticas fundamentales. Por ello, del mismo modo que en el ring no cabe un resultado pactado, las disputas en torno a estos conceptos no pueden resolverse jamás mediante una simple estipulación convencional de significado. Tienen una carga emotiva tan intensa que nadie con aspiraciones de incidir sobre la realidad social de una comunidad puede renunciar a su uso; se trata de entrar en el ring y usar el concepto con el fin de ganar una disputa político-social. Si bien se considera, las tres primeras propiedades no les atribuyen el carácter de «esencialmente controvertidos». La cuarta, la que viene a determinar que su papel es meramente dialéctico ${ }^{30}$, es la que excluye que tenga sentido hablar de interpretación de tales conceptos. Pues bien, quien entienda que los conceptos valorativos presentes en las constituciones son así (que no tienen ninguna zona de claridad y que su función es meramente dialéctica) habrá sentado las bases para un claro escepticismo interpretativo que resulta especialmente idóneo para las lecturas procedimentalistas (antisustantivistas) de las constituciones ${ }^{31}$.

${ }^{28}$ Cfr. W. B. Gallie, «Essentially Contested Concepts», en Proceedings of the Aristotelian Society, 56, 1956, 385-402, y J. WALDRON, «Vagueness in Law and Language: Some Philosophical Issues», en California Law Review, vol. 82, núm. 3, 509-540.

29 M. IGLESIAS VILA, «Los conceptos esencialmente controvertidos en la interpretación constitucional», en Doxa, núm. 23, 2000, 77 y ss.

30 En este sentido, más allá del arbitrismo y del voluntarismo que destila, creo que en el siguiente párrafo SCHMITT se encuentran no pocas bases para interpretar los conceptos políticos como esencialmente controvertidos: «[...] todos los conceptos, ideas y palabras poseen [en el ámbito de lo político] un sentido polémico; se formulan con vistas a un antagonismo concreto, están vinculados a una situación concreta cuya consecuencia última es una agrupación según amigos y enemigos (que se manifiesta en guerra o revolución), y se convierten en abstracciones vacías y fantasmales en cuanto pierde vigencia esa situación. Palabras como estado, república, sociedad, clase, o también soberanía, estado de derecho, absolutismo, dictadura [...], etc., resultan incomprensibles si no se sabe a quién en concreto se trata en cada caso de afectar, de combatir, negar y refutar con tales términos». C. Schmitt, El concepto de lo político (trad. R. AgAPITO), Madrid, Alianza, 1991,60 y 61.

31 Llevado a su extremo esta forma de concebir los conceptos valorativos desemboca no solo en concepciones procedimentalistas del constitucionalismo, sino en concepciones abiertamente anticonstitucionalistas. Un claro ejemplo de procedimentalismo anticonstitucionalista son los trabajos de WALDRON. Vid., por ejemplo, J. WALDRON, «A Right-Based Critique of Constitutional Rights», en Oxford Journal of Legal Studies, vol. 13, núm. 1, 1993, 18-51, y J. WALDRON, Law and Disagreement, Oxford, Clarendon Press, 1999. 


\subsection{Sobre la «constitución resistente». En memoria de Francisco ToMÁs Y VALIENTE ${ }^{32}$}

\section{Escribe TOMÁS Y VALIENTE:}

La resistencia de la Constitución puede ser entendida como adaptabilidad a la dinámica política [...] también como su capacidad para ser interpretada de forma flexible y hasta cierto punto cambiante en función de nuevos problemas y nuevas sensibilidades o exigencias a propósito de los derechos fundamentales en ella positivizados, pero no definidos. Y además como resistencia a la reforma, haciéndola innecesaria [...] Si la rigidez implica prohibición o dificultad de reforma [...] resistencia significa adaptabilidad al cambio haciendo innecesaria la reforma [...] Creo que puede formularse la hipótesis de que una Constitución dotada de mecanismos acertados para hacerla resistente en el sentido expuesto, protege su supremacía y alcanza una vigencia efectiva y duración prolongada, sin tener que pagar el precio de las reformas agravadas ${ }^{33}$.

En un trabajo destinado a teorizar la noción de «resistencia constitucional» de TOMÁS Y VALIENTE sostuve ${ }^{34}$ que cualquier redactor de una constitución que fuera consciente, por un lado, del problema de la tiranía de las generaciones pasadas y, por otro, de los problemas de consenso y de compromiso, se vería limitado en su tarea por una función que relacionara la rigidez y la apertura constitucionales. Esta función vendría a determinar que si hay problemas de consenso y/o de inseguridad práctica, a medida que se incrementa la rigidez constitucional tiene que incrementarse también la apertura regulativa. Naturalmente ahí no se decía nada a propósito del punto óptimo de equilibrio entre ambas variables. Esta función estaba pensada para los procesos de redacción de las constituciones, pero no es difícil darse cuenta de que la misma puede proyectarse también sobre la cuestión de las peculiaridades de la interpretación constitucional. Si bien se considera, la tesis de la diferencia sostenida en los dos epígrafes anteriores puede sintetizarse en la siguiente máxima: cuanto más rígida es una constitución regulativa (es decir, cuanta más distancia hay entre forma constitucional y forma legal), más valorativa y menos autoritativa debe ser su interpretación.

\section{3. ¿CÓMO SE HACE HABLAR A LA CONSTITUCIÓN CON UNA SOLA VOZ?}

La primera pregunta que nos hemos formulado nos ha llevado a sostener que interpretar es asignar un significado a un texto, en nuestro caso a un texto constitucional. La segunda pregunta nos ha llevado a abordar la cuestión de los criterios y/o los ar-

32 F. TOMÁs y VALIENTE fue magistrado del Tribunal Constitucional español entre 1980 y 1992 y lo presidió entre 1986 y 1992. En 1996, fue asesinado por ETA.

33 F. TOMÁs y VALIENTE, «La resistencia constitucional y los valores», en Doxa. Cuadernos de Filosofía del Derecho, núms. 15-16, vol. II, 1994, 639. La noción de resistencia constitucional puede usarse como un verdadero alegato en contra de la lectura «originalista» de las constituciones. En este sentido, apunta en la misma dirección que la noción de «constitución viviente», D. STRAuss, The living Constitution, New York-Oxford, Oxford University Press, 2010.

34 J. Aguiló Regla, «Sobre el constitucionalismo y la resistencia constitucional», en Doxa. Cuadernos de Filosofía del Derecho, núm. 26, 2003, 289-319. 
gumentos que guían y/o justifican la interpretación constitucional; y hemos sostenido que las propiedades de la rigidez y de la apertura regulativa permiten sostener la tesis de la diferencia entre la interpretación de la constitución y la interpretación de la ley. La tercera pregunta nos enfrenta directamente con el problema de la unidad del derecho, aunque aquí — dado que hablamos de interpretación constitucional — nos lleve a la cuestión de la unidad de la constitución. Pero antes que nada, antes de hablar de respuestas al problema, tratemos de entender bien en qué consiste el problema de la unidad del derecho y/o de la constitución.

El problema de la unidad de la constitución y/o del derecho es el siguiente. Cuando resolvemos un problema constitucional nos encontramos con fenómenos tan normales como que un mismo artículo puede recibir interpretaciones contradictorias entre sí o que diversos textos de una misma constitución pueden apuntar en direcciones incompatibles, etc. Es decir, nos podemos topar con defectos como las antinomias, las lagunas, las imprecisiones, las incoherencias valorativas y un largo etcétera. Ahora bien, todo jurista sabe que al final de un razonamiento jurídico acabado la diversidad de sentidos, de normas aplicables, de soluciones posibles, etc., se reduce a la unidad del derecho o de la constitución. Esto es así porque el derecho es práctico y al final tiene que ser resolutivo (por ejemplo, ¿prohíbe o no la constitución española el matrimonio entre personas del mismo sexo?). Esto lo sabe todo el mundo. El problema es explicar cómo se produce esa unificación, porque la unidad del derecho y/o de la constitución, ¿tiene fundamento o simplemente se decide? $\mathrm{O}$ formulado en otros términos aunque el problema sea el mismo: ¿tienen los casos una única respuesta correcta?

Para arrojar algo de luz respecto de este punto quiero referirme a dos cosas diferentes. La primera es el papel que juegan las concepciones constitucionales en la construcción de la unidad de la constitución. La segunda es la proyección sobre el problema de la unidad de la constitución de tres actitudes básicas en relación con la unidad del derecho en general.

\subsection{El papel de las concepciones constitucionales en la construcción de la unidad de la constitución}

Las diferentes concepciones constitucionales proponen, por un lado, diseños constitucionales para las fases de redacción de las constituciones o de enmienda de las ya existentes y, por otro, lecturas o criterios interpretativos de las constituciones existentes, de las constituciones positivas. El primer caso no es relevante a los efectos de la interpretación constitucional; el segundo, sí. Aquí no puedo detenerme a hacer un repaso de las principales concepciones constitucionales. Ello nos llevaría demasiado lejos. Sí quiero, sin embargo, llamar la atención sobre una confusión que es muy común. En efecto, cuando las concepciones constitucionales formulan propuestas de lectura, suministran criterios para la interpretación de las constituciones ya existentes, a veces se produce una cierta confusión entre las propiedades o características de una constitución y las concepciones o las teorías de esa misma constitución. Este error es muy común y genera una gran distorsión en la discusión constitucional; por- 
que, por ejemplo, una cosa es afirmar que una determinada constitución es democrática y otra muy distinta, defender una lectura democrática de esa misma constitución. La diferencia radica en que mientras que en el primer caso lo que se está diciendo es que la democracia es una de las propiedades o características de la constitución en cuestión, en el segundo lo que se afirma es que esa propiedad, la de ser una constitución democrática, debe prevalecer frente a otras posibles propiedades de esa misma constitución que pudieran entrar en conflicto con ella. En este sentido, las distintas concepciones de la constitución lo que hacen es tomar una o varias propiedades de la constitución y elevarlas a la categoría de propiedades «rectoras» de esa constitución. El garantismo, el originalismo, el procedimentalismo, el mecanicismo, el sustantivismo, el principialismo, etc., en cuanto concepciones de la constitución no niegan que junto a ciertas propiedades de la constitución coexistan otras, lo que afirman es que en caso de incertidumbre, indeterminación, conflicto, etc., cierta propiedad de la constitución debe prevalecer sobre las demás. Las disputas entre concepciones de la constitución no versan sobre las propiedades que caracterizan a una constitución, sino sobre la preeminencia de unas sobre otras. No se trata de disputas sobre cómo deben ser descritas las cosas (no se discuten las propiedades de una constitución), sino sobre cómo deben ser preferidas (se discute qué propiedad pesa más en caso de conflicto). Si se tiene claro esto, es fácil comprender el papel de «mediación» que juegan las concepciones constitucionales en la construcción de la «unidad de la constitución», en el proceso de hacer hablar a la constitución con una sola voz. Naturalmente, este papel de las concepciones constitucionales es argumentativo y justificativo ${ }^{35}$.

\section{2. ¿Tienen los casos una única respuesta correcta?}

Respecto de esta pregunta caben tres respuestas básicas: Sí, a veces y nunca. Con las variables que hemos venido barajando hasta aquí, estas tres respuestas pueden hacerse coincidir con tres grandes concepciones del derecho que se proyectan sobre la interpretación del derecho, en general, y de la constitución, en particular. La concepción del derecho como práctica, la concepción del derecho como sistema y la concepción crítica del derecho. Aquí, como imagino que se comprenderá, no puedo detenerme a explicarlas. El siguiente cuadro muestra algunos corolarios que pueden extraerse de estas tres concepciones sobre el problema de la unidad del derecho a propósito de la interpretación constitucional.

35 Lo que se acaba de decir respecto de las concepciones constitucionales no puede resultar extraño a ningún jurista acostumbrado a leer y a participar en las frecuentes y eternas discusiones relativas a las «naturalezas jurídicas» de las instituciones. Más allá del hecho de que esas discusiones tienden a estar presididas por un sinfín de enredos y a ocultar los términos sobre los que realmente versan, en lo arriba expuesto están dadas las claves para la comprensión de las mismas. Las discusiones a propósito de las naturalezas jurídicas son discusiones normativas destinadas a aclarar el alcance de un concepto o institución (es decir, sólo son operativas ante casos que no son claros); para ello se trata generalmente de determinar qué propiedad dentro del conjunto de propiedades que caracterizan al concepto o institución opera como propiedad «rectora» (la que determina su «esencia o naturaleza» y que permite definir prioridades entre esas propiedades); y, finalmente, son claramente argumentativas y justificativas (se trata siempre de ofrecer razones en favor de una determinada interpretación). 


\section{¿Tienen los casos una única respuesta correcta?}

\begin{tabular}{|c|c|c|}
\hline Sí & A veces & Nunca \\
\hline $\begin{array}{l}\text { El derecho como prác- } \\
\text { tica }\end{array}$ & El derecho como sistema & $\begin{array}{l}\text { El derecho presenta una indeter- } \\
\text { minación radical. }\end{array}$ \\
\hline $\begin{array}{l}\text { La constitución es una } \\
\text { unidad dotada de sen- } \\
\text { tido. }\end{array}$ & $\begin{array}{l}\text { La constitución es un con- } \\
\text { junto de enunciados cuya } \\
\text { unidad es relativa a los ca- } \\
\text { sos. }\end{array}$ & $\begin{array}{l}\text { La constitución es esencialmente } \\
\text { contradictoria en términos valo- } \\
\text { rativos. }\end{array}$ \\
\hline $\begin{array}{l}\text { - Hay una respuesta } \\
\text { correcta para cada } \\
\text { caso. } \\
\text { - La única respuesta } \\
\text { correcta expresa un } \\
\text { ideal regulativo de } \\
\text { la práctica constitu- } \\
\text { cional. }\end{array}$ & $\begin{array}{l}\text { - En los casos resueltos } \\
\text { por el sistema hay una } \\
\text { única respuesta correc- } \\
\text { ta. } \\
\text { - En los casos no resuel- } \\
\text { tos, la unidad se decide. }\end{array}$ & $\begin{array}{l}\text { - Nunca hay una única respues- } \\
\text { ta correcta. } \\
\text { - La única respuesta correcta } \\
\text { como ideal regulativo es falsa } \\
\text { conciencia. } \\
\text { - El derecho como sistema es } \\
\text { falsa conciencia. }\end{array}$ \\
\hline Caso fácil/caso difícil. & $\begin{array}{l}\text { Caso regulado/caso no re- } \\
\text { gulado. }\end{array}$ & $\begin{array}{l}\text { El intérprete puede presentar to- } \\
\text { dos los casos como regulados/no } \\
\text { regulados o como fáciles/difíciles. } \\
\text { Instrumentaliza las clasificacio- } \\
\text { nes. }\end{array}$ \\
\hline $\begin{array}{l}\text { Énfasis en la dimensión } \\
\text { valorativa del derecho. }\end{array}$ & $\begin{array}{l}\text { Énfasis en la dimensión au- } \\
\text { toritativa del derecho. }\end{array}$ & $\begin{array}{l}\text { Énfasis en la dimensión instru- } \\
\text { mental del derecho. }\end{array}$ \\
\hline $\begin{array}{l}\text { Concepción constructi- } \\
\text { vista y/o interpretativis- } \\
\text { ta del derecho }\end{array}$ & $\begin{array}{l}\text { Concepción convenciona- } \\
\text { lista y/o sistemática del de- } \\
\text { recho }\end{array}$ & $\begin{array}{l}\text { Concepción instrumentalista y/o } \\
\text { crítica del derecho }\end{array}$ \\
\hline
\end{tabular}

\section{4. ¿CÓMO CONCEBIMOS (O DEFINIMOS) LA CONSTITUCIÓN DEL ESTADO CONSTITUCIONAL?}

\subsection{Dos maneras de concebir el Estado constitucional}

La cuestión es clara: según cómo construyamos el objeto constitución extraeremos unos u otros corolarios interpretativos. Aquí no voy a detenerme en toda la complejidad que entraña el concepto de constitución. Lo que sí voy a hacer es contraponer dos grandes formas de concebir (identificar, definir) «jurídicamente» (es decir, en cuanto juristas) la constitución del Estado constitucional. La primera, inspirada en el constitucionalismo garantista de FERRAJOLI, vendría a sostener que la constitución del Estado constitucional se define solo por lex superior; la segunda, que podríamos llamar «constitucionalismo principialista», sostendría que la constitución del Estado constitucional se define por lex superior más ciertos contenidos necesarios (definitorios). 


\section{Escribe y estipula FERRAJOLI ${ }^{36}$ :}

Así, será conveniente utilizar la expresión «ius-constitucionalismo» o «constitucionalismo jurídico», o mejor aun «estado constitucional de derecho» o simplemente «constitucionalismo», para designar [...] al constitucionalismo rígido [...] En este sentido, el rasgo distintivo del constitucionalismo será la existencia positiva de una lex superior a la legislación ordinaria, con independencia de las diversas técnicas adoptadas para garantizar su superioridad [...] [en el original pp. 6 y 7. La cursiva es mía]

La finalidad [de este escrito, el de FERRAJOLI] es sostener [...] una concepción del constitucionalismo estrictamente «iuspositivista», entendiendo por «positivismo jurídico» una concepción y/o un modelo de derecho que reconoce como «derecho» a todo conjunto de normas puestas o producidas por quien está habilitado para producirlas, con independencia de cuáles fueren sus contenidos y, por tanto, de su eventual injusticia [en el original pp. 1 y 2].

Frente a esta forma de entender el Estado constitucional hay que afirmar que no todo Estado que tiene una constitución (una constitución rígida y regulativa: la lex superior de la que habla FeRRAJOLI) es un Estado constitucional ${ }^{37}$. Por sí misma la lex superior identifica tan poco al Estado constitucional de derecho como la lex posterior al Estado legal (o legislativo) de derecho. El «Estado de derecho», en general, no es simplemente observable a partir de puros rasgos estructurales. La rigidez constitucional orientada a preservar la «verdadera religión» (es decir, a negar la libertad religiosa) es incompatible con lo que llamamos Estados constitucionales. Lo que propone FERRAJOLI es que seamos leales al positivismo aunque para ello debamos vaciar el garantismo. La insuficiencia de sus planteamientos proviene de la necesidad de dotar de valor y de sentido a las referidas propiedades estructurales. Entre otras cosas, porque la rigidez y la normatividad de las constituciones sólo son valiosas (no en vano se trata de puras técnicas de protección) en la medida en que sean garantía de cosas a su vez consideradas valiosas. Estas mismas técnicas al servicio, por ejemplo, no de una expectativa considerada valiosa y, por tanto, merecedora de ser protegida en forma de un derecho, sino de un privilegio (es decir, de una expectativa no valiosa y/o no justificada) resultan simplemente insoportables e irracionales. Sólo si se introduce el componente de valor inserto en las constituciones tiene sentido, en mi opinión, a diferencia de lo sostenido por FERRAJOLI, hablar de «garantismo».

36 L. FERRAJOLI, «Constitucionalismo principialista y constitucionalismo garantista» (trad. de N. Guzmán) en Doxa. Cuadernos de Filosofía del Derecho, núm. 33, 2011 (en prensa).

37 Hace ya muchos años, en 1966, E. DíAz comenzaba su conocidísimo libro Estado de derecho y sociedad democrática con un lapidario «No todo Estado es un Estado de derecho». Esta frase pretendía cumplir algunas funciones coyunturales vinculadas a la resistencia democrática española a la dictadura franquista; pero la frase en cuestión tenía (y tiene) un sentido teórico que trasciende con mucho a aquella coyuntura política. El concepto de «Estado de derecho», viene a decir la frase, no es sólo un concepto descriptivo-clasificatorio, es también - y de manera muy relevante- un concepto valorativo. Ello es muy importante por lo siguiente: el Estado de derecho no coincide simplemente con la juridicidad o la legalidad como parecen suponer muchos juristas positivistas. Si así fuera, todo Estado moderno sería un Estado de derecho, pues ningún Estado puede prescindir del derecho como un instrumento para guiar y controlar las conductas. Es, pues, un concepto normativo/valorativo cuya función no es describir una mera propiedad del derecho moderno. Es un concepto normativo/ valorativo, resultado de la asunción de ciertas exigencias ético-políticas y que sirve para evaluar los diferentes sistemas jurídico-positivos ( $c f r$. F. LAPORTA, «Imperio de la ley. Reflexiones sobre un punto de partida de Elías Díaz», en Doxa. Cuadernos de Filosofía del Derecho, núms. 15-16, vol. I, 1994, 133 y ss.). Por ello, porque el concepto de «Estado de derecho» tiene la referida naturaleza normativo-valorativa, se explica que en torno a él puedan desarrollarse las actitudes crítico-prácticas propias de un «aceptante». Con el concepto de «Estado constitucional de derecho» ocurre exactamente lo mismo. 
Una garantía independizada del valor de lo garantizado es, me parece, un sinsentido práctico.

En cualquier caso, y más allá de la discusión con FERRAJOLI, lo que me interesa resaltar es que hay dos grandes formas de definir en términos jurídicos la constitución del Estado constitucional: una, toma como rasgo definitorio del Estado constitucional sólo la forma constitucional (la lex superior), mientras que la otra incluye junto a la forma constitucional ciertos contenidos «necesarios». El siguiente cuadro resume algunos corolarios que se siguen de las mismas:

\section{Estado constitucional definido}

\begin{tabular}{|l|l|}
\hline \begin{tabular}{c} 
a) \\
\multicolumn{1}{|c|}{$\begin{array}{c}\text { Sólo por Lex Superior (consti- } \\
\text { tucionalismo garantista) }\end{array}$}
\end{tabular} & $\begin{array}{c}\text { b) Por Lex Superior más ciertos contenidos necesarios } \\
\text { (constitucionalismo principialista) }\end{array}$ \\
\hline $\begin{array}{l}\text { Todo Estado con lex superior es un } \\
\text { Estado constitucional. }\end{array}$ & $\begin{array}{l}\text { No todo Estado con lex superior es un Estado constitu- } \\
\text { cional. }\end{array}$ \\
\hline $\begin{array}{l}\text { La Constitución es una «fuente- } \\
\text { acto»y todo en ella es decidido. }\end{array}$ & $\begin{array}{l}\text { La Constitución es una fuente-acto. Se decide la formu- } \\
\text { lación de todas las normas, pero hay normas necesarias. }\end{array}$ \\
\hline $\begin{array}{l}\text { La explicación jurídica de todas } \\
\text { las normas constitucionales remite } \\
\text { al poder constituyente. }\end{array}$ & $\begin{array}{l}\text { La explicación jurídica de algunas normas constitucio- } \\
\text { nales remite al poder constituyente; la de otras, no. }\end{array}$ \\
\hline $\begin{array}{l}\text { Todos los derechos son constitui- } \\
\text { dos. }\end{array}$ & Algunos derechos son reconocidos. \\
\hline $\begin{array}{l}\text { Los argumentos metaformales son } \\
\text { metaconstitucionales. }\end{array}$ & $\begin{array}{l}\text { Los argumentos metaformales no son necesariamente } \\
\text { metaconstitucionales. }\end{array}$ \\
\hline
\end{tabular}

Expliquemos un tanto el cuadro, tratando de justificar sobre todo la opción b). Es evidente que en un sistema jurídico-político que cuenta con la «forma constitucional» (es decir, con una «constitución formal») se ha tomado una «decisión» respecto de qué cuenta como constitución dentro de ese sistema jurídico-político, pero de ahí no se sigue nada suficiente para la identificación del Estado constitucional. Sólo algunos Estados que cuentan con una constitución formal, rígida y regulativa son Estados constitucionales de derecho: aquellos cuyas constituciones satisfacen ciertos «contenidos». Lo característico (y distintivo) no está sólo en la forma ni sólo en la sustancia. Sino en que la forma (la lex superior) opera como garantía de una cierta sustancia, no de cualquier sustancia. Si uno acepta este elemental razonamiento se ve abocado a extraer el siguiente corolario. En toda constitución de un Estado constitucional hay normas y principios necesarios. No es concebible un Estado constitucional sin derecho a la libertad de expresión, sin derecho de asociación, sin democracia o sin los principios de independencia e imparcialidad de los jueces, etc. Sin esos derechos y/o principios habrá lex superior pero no Estado constitucional de derecho. Es discutible cuál es el contenido «esencial» del Estado constitucional (aquél sin el cual no podría hablarse de Estado constitucional), pero lo que, en mi opinión, resulta indudable es que ese con- 
tenido no se identifica sólo por la forma jurídica que adopta. Es, más bien, al revés: se le da cierta forma a un contenido porque se lo considera fundamental. Entender el Estado constitucional supone darse cuenta de que, a pesar de que la constitución es una fuente-acto, hay un núcleo en el cual opera el tan denostado por Ferrajoli veritas, non auctoritas, facit legem. Tomemos como ilustración de lo que se quiere decir el art. 16 de la $\mathrm{CE}^{38}$. Es trivialmente cierto que la forma constitucional iguala los apartados 1 (reconocimiento de la libertad ideológica, religiosa y de culto) y 3 (deber de cooperación de los poderes públicos con la Iglesia Católica) de dicho artículo. No hay duda, ambos apartados son igualmente fragmentos de la Constitución española. Pero de ahí no se sigue que «pesen» lo mismo en términos jurídicos. El apartado 1 expresa un principio necesario del constitucionalismo democrático (de forma tal que si ese contenido fuera eliminado del texto y/o de la práctica constitucional difícilmente diríamos que estamos ante un Estado constitucional de derecho), mientras que el apartado 3 expresa todo lo más un contenido idiosincrásico (podría no formar parte de la Constitución española o ser derogado sin que ello afectase a la calificación del orden jurídico-político español como Estado constitucional). Detrás de esta afirmación hay argumentos «no formales», «para-formales» o «meta-formales», pero en ningún caso, meta-constitucionales o meta-jurídicos; pues es el producto de entrar a «ponderar» sustancia jurídica y de tomar en consideración, dentro de las normas constitucionales, la distinción entre normas necesarias y normas contingentes (es decir, idiosincrásicas) ${ }^{39}$.

\subsection{La distinción entre normas necesarias y normas contingentes (idiosincrásicas)}

Como ya he dicho, en toda constitución de un Estado constitucional hay normas y principios necesarios que son inderogables. No sólo en el sentido de que la rigidez constitucional hace difícil (o altamente improbable) la derogación de su formulación normativa; sino en el sentido de que si se derogan, entonces el Estado en cuestión dejaría de ser un Estado constitucional. Por ejemplo, no es concebible la derogación del principio de libertad de expresión, o del de independencia de los jueces, o del derecho de asociación; pueden cambiar las respectivas formulaciones normativas en que se «reconocen» esos principios y/o derechos, pero no es posible su eliminación como principios y derechos y seguir hablando de Estado constitucional de derecho. Son, en este sentido, principios necesarios del Estado constitucional de derecho. En mi opinión, esto constituye una obviedad. Tan es así que, por ejemplo como una cuestión de hecho, nadie acude a la noción de poder constituyente para explicar por qué esos principios forman parte de la Constitución española. Se asume que si esos principios y/o derechos no es-

38 Art. 16: «1. Se garantiza la libertad ideológica, religiosa y de culto de los individuos y las comunidades sin más limitación, en sus manifestaciones, que la necesaria para el mantenimiento del orden público protegido por la Ley.

2. Nadie podrá ser obligado a declarar sobre su ideología, religión o creencias.

3. Ninguna confesión tendrá carácter estatal. Los poderes públicos tendrán en cuenta las creencias religiosas de la sociedad española y mantendrán las consiguientes relaciones de cooperación con la Iglesia Católica y las demás confesiones».

39 Esta distinción está inspirada en la oposición entre «normas comunes» y «normas idiosincrásicas» en el derecho constitucional europeo. Sobre ello, vid. A. J. MENÉNDEZ, «Sobre los conflictos constitucionales europeos. Validez del derecho comunitario y legitimidad democrática de la Unión Europea», en Anuario de Filosofía del Derecho, 2007, 139 y ss. 
tuvieran en la Constitución española, el constituyente español no habría constituido un Estado constitucional. En relación con estos contenidos explica bastante más la noción de «pretensión de corrección» que la noción de «voluntad del poder constituyente». $\mathrm{Y}$, en este sentido, desde una perspectiva constructivista son mucho más expresión de un consenso ideal que de un consenso fáctico. Quien entienda lo anterior, entenderá por qué en el proceso de internacionalización del derecho constitucional hay ciertas normas que empiezan a jugar un genuino papel de «derecho común» en lugar del de un simple derecho comparado: en este sentido es muy importante el rol que juegan hacia el interior de los Estados constitucionales, por un lado, la jurisprudencia de los tribunales internacionales de derechos humanos y, por otro, la circulación de precedentes entre distintos tribunales constitucionales. Estos procesos no son sólo ni mucho menos el producto de una coordinación de constituyentes, sino el producto del desarrollo de una práctica y una conciencia de generación de un derecho constitucional común.

En toda constitución «positiva» de un Estado constitucional hay también normas que expresan contenidos «idiosincrásicos»; es decir, contenidos cuya explicación va referida a las peculiaridades históricas y sociales de cada Estado constitucional. En este sentido, en cada constitución hay normas cuya explicación necesita de la noción de poder constituyente; entendido éste como expresión de la singularidad histórica de cada Estado constitucional. Por ejemplo, la noción de poder constituyente es superflua para explicar por qué la Constitución española reconoce la libertad de expresión, pero es esencial para explicar por qué España es una monarquía y no una república. Es superflua para explicar el reconocimiento de la libertad religiosa pero es básica para explicar el deber de cooperación con la Iglesia Católica. Es decir, hay todo un ámbito en las constituciones positivas en el que es cierto el dictum de «auctoritas, non veritas, fácit legem». Desde una perspectiva constructivista, todas estas normas expresan no un consenso ideal, sino un consenso fáctico. Finalmente, en relación con el proceso de internacionalización del derecho constitucional, estas normas dan lugar a un derecho constitucional comparado, no a un derecho constitucional común.

La adopción de un concepto no meramente formal de constitución y la asunción de esta distinción, $\mathrm{u}$ otra semejante, tiene una honda repercusión en la interpretación de las constituciones positivas. A modo de ejemplo, y ya para concluir, considérense las tres siguientes cuestiones:

a) ¿Puede haber principios constitucionales no formulados en la constitución positiva? En mi opinión, sí. La Constitución española suministra un espléndido ejemplo al respecto. En efecto, el título VI, «Del poder judicial», no hace ninguna alusión a la imparcialidad de los jueces, al principio de imparcialidad; habla de independencia, inamovilidad, responsabilidad y sometimiento al imperio de la ley. La pregunta importante que hay que responder es si conforme al Estado constitucional español el principio de imparcialidad judicial está o no a disposición del legislador. Es decir, si el legislador mediante ley puede ponerlo o quitarlo según su parecer. En mi opinión, el principio de imparcialidad judicial es un principio constitucional aunque la constitución promulgada no lo reconozca y, en consecuencia, no es disponible por el legislador. Podría sostenerse que en realidad no se trata de un principio necesario sino simplemente de un principio implícito, pues podría extraerse por interpretación del resto de normas constitucionales. Sin duda ello es así, pero mi tesis pretende ser más 
fuerte y es esta: no puede haber (no es concebible el) Estado constitucional de derecho sin principio de imparcialidad judicial. Y si las cosas son así, entonces el principio de imparcialidad judicial es un principio necesario del Estado constitucional de derecho.

b) En caso de conflicto y/o ponderación entre una norma necesaria y una norma idiosincrásica, ¿cuál debe prevalecer? Es evidente, en mi opinión, que si el razonamiento constitucional fuera meramente ideal debería prevalecer siempre la norma necesaria, es decir, el consenso ideal frente al consenso fáctico (histórico). Ahora bien, las cosas son generalmente más complicadas. En este sentido, conviene retomar la idea de práctica constitucional al completo, con sus componentes ideales y fácticos. El valor de los componentes idiosincrásicos de la práctica constitucional proviene en gran medida de haber hecho posible la práctica de los componentes ideales del constitucionalismo; y, en muchas ocasiones, la continuidad de los elementos idiosincrásicos aparece como condición necesaria para la continuidad de los componentes ideales. En este sentido, podría decirse que en ocasiones colapsa la distinción valorativa entre unos y otros componentes. Por poner un ejemplo bastante evidente de la Constitución española: la Corona no es ni por asomo un componente ideal y/o necesario del constitucionalismo; sin embargo, en España, durante mucho tiempo, ha circulado el «tópico» de que la continuidad de la Monarquía es una garantía de la continuidad de los componentes ideales del constitucionalismo. En este sentido, la idea de práctica constitucional vincula en muchas ocasiones el valor de unos a otros ${ }^{40}$.

c) Tomando en consideración la distinción aquí asumida, ¿tiene sentido hablar de normas constitucionales espurias? La idea de norma espuria no alude como el punto anterior a un caso de colisión y/o ponderación entre una norma necesaria y una norma idiosincrásica. Se trata de otra cosa: hablar de normas constitucionales espurias supone hablar de: a) normas de la constitución positiva; b) que expresan un contenido idiosincrásico (son el producto de una voluntad), y c) se juzgan inválidas desde los principios necesarios del Estado constitucional de derecho. La cuestión es obviamente compleja y controvertida; y no voy a detenerme ahora en ella. Si quiero, sin embargo, hacer una advertencia: quien sostenga que las Cortes constitucionales tienen competencia para juzgar (controlar) en términos sustantivos y no meramente procedimentales el ejercicio del poder de reforma constitucional, tiene que admitir la posibilidad conceptual de la existencia de «normas constitucionales espurias». Dicha competencia sólo puede justificarse para preservar (evitar la derogación de) los principios necesarios del Estado constitucional y para prevenir la promulgación de normas espurias en relación con los parámetros definitorios del Estado constitucional de derecho.

\section{CONCLUSIONES}

En esta ponencia, más allá de los diferentes análisis que se han ido realizando a lo largo del texto, he procurado justificar dos tesis relativas a la «interpretación constitu-

40 En este punto, aunque no coinciden exactamente con lo aquí sostenido, son plenamente relevantes todas las consideraciones que hace C. S. NINO en relación con la aceptación del control judicial de constitucionalidad frente a decisiones democráticas para preservar «la continuidad de la práctica constitucional». Cfr. C. S. Nino, Fundamentos de derecho constitucional. Análisis filosófico, jurídico y politológico de la práctica constitucional, Buenos Aires, Astrea, 1992, 701 y ss. 
cional» o, mejor dicho, a la «interpretación de la constitución de un Estado constitucional»:

1. La tesis de la diferencia interpretativa entre constitución y ley: cuanto más rígida es una constitución regulativa (es decir, cuanta más distancia hay entre forma constitucional y forma legal), más valorativa y menos autoritativa debe ser su interpretación.

2. La tesis de la relevancia interpretativa de la distinción, dentro de las normas constitucionales, entre «normas necesarias» y «normas idiosincrásicas». 